\title{
Traffic Capacity Analysis in a One-Lane Roadwork Zone
}

\author{
Dovydas Skrodenis ${ }^{1 *}$, Donatas Čygas ${ }^{2}$, Ieva Jakubėnaite ${ }^{3}$ \\ ${ }^{1,3}$ Road Research Institute, Vilnius Gediminas Technical University, Vilnius, Lithuania \\ ${ }^{2}$ Road Department, Vilnius Gediminas Technical University, Vilnius, Lithuania
}

Received 04 February 2020; accepted 31 March 2020

\begin{abstract}
Interventions to road are always required to keep road network in a good condition for this reason road works such as maintenance or reconstruction are carried out regularly. Roadwork zone distorts typical driving conditions and brings many unknown factors to driving process that increase the likelihood of an accident or congestion formation. Roadworks zones in Lithuania are a serious problem due to congestion formation, therefore, before the real construction works, it is necessary to carry out traffic flow and capacity modeling as well as to choose the appropriate traffic organization scheme through roadworks zones. The biggest congestion of vehicles in Lithuania occurs in roadworks zones where there is one lane left and traffic is controlled by traffic light, which do not adapt to real traffic conditions, but operate according to the created cycle and frequency model. The simulation analysis of roadwork zone with temporary traffic lights, in order to select optimal green light cycle and frequency is represented, in this paper.
\end{abstract}

Keywords: roadwork zone, traffic capacity, traffic simulation model, roadwork simulation.

\section{Introduction}

Simulation by computer software has been widely endorsed and applied in various domains for decades. This action has been shown to be a cost effective and decisive methodology for what-if analyses examination before field work begins. Successful applications of computer simulation help reduce the possibility of rework, control project budget or predict project duration (Hadiuzzaman et al., 2014). The variety of simulation software is wide enough to choose from, however each software may be using different prediction algorithms, as well as final simulation results may differ for each simulation tool. Basically, simulation tools are divided into several categories for their detail at exact points: microscopic, mesoscopic and macroscopic. Traffic impacts can be accurately estimated using microscopic simulation models due to their ability to simulate individual vehicles and their interactions that can have a strong impact on various performance measures such as capacity, queue length, and travel delays.

Typically, construction and maintenance activities involve single or multiple lane closures for a certain duration of time. The scheduling of lane closures and work activity is done primarily based on the expected length of queues at the work zone. Traffic engineers determine the expected queue lengths based on a combination of their past experience and analysis tools (Chatterjee, 2008). Birst et al. (2007) compared microscopic simulation tools such as VISSIM, SIMTRAFFIC and CORSIM with HCM 2000 under various traffic scenarios. Author suggested that if simulation model parameters (inputs) are well calibrated they can produce results that are identical to the results produced by the well accepted HCM methodology. On the other hand, Schnell et al. (2002) opposed that the simulation models can not replicate oversaturated travel conditions which is common phenomenon in work zones with considerable queue formation. This is mainly due to the lack of proper guidelines to calibrate such models.

\section{Background}

A work zone is a section of roadway with construction or maintenance related work activities. These activities are mostly periodical but could be critical for a safe and efficient transportation system (Ng \& Waller, 2010; Debnath \& Blackman, 2014; Chen \& Tarko, 2014; Wu et al., 2013). Some authors indicate work zones as critical nodes of the road network in terms of road safety as they entails deviations from frequent driving conditions in a discrete road section (La Torre et al., 2017). Base-lining Road Works Safety on European Roads [BRoWSER] (2004) indicates the probability of traffic accident is less if all vehicles are speeding through roadwork zone instead of substantial speed differences. Deviations from typical driving conditions forms queues which is the main reason of different speed appearance in roadwork zones.

\footnotetext{
*Corresponding author. E-mail: dovydas.skrodenis@vgtu.lt
}

\section{Copyright (C) 2020 The Author(s). Published by VGTU Press}

This is an Open Access article distributed under the terms of the Creative Commons Attribution License (http://creativecommons.org/licenses/by/4.0/), which permits unrestricted use, distribution, and reproduction in any medium, provided the original author and source are credited. 
Work zones can occur on different categories of roads and at different locations, therefore default solutions are not always suitable to ensure efficient traffic management. Basically, simulating traffic congestion in road work zones can be divided into two categories: calculating flows using expert knowledge and formulas or trying to recreate real driving conditions in the model. The purpose of both different calculation methods is to find possible time wastage and their costs. It is a complex task to calculate monetary loss accurately because of dynamic criteria in each road work zone. The Highway Capacity Manual provides a preliminary principle for calculating traffic capacity for work zones. Formula includes three input criteria: (1) the presence of heavy vehicles; (2) type, intensity, and location of work activity; and (3) on-ramp presence. This calculation method is very abstract and does not take into account the surrounding factors such as weather conditions, local transport connections, etc. Carr (2000) developed a Construction Congestion Cost system (CO 3) for the Michigan Department of Transportation to facilitate a balance between construction productivity and traffic delay. This is a loss calculation algorithm developed in excel sheet where specific values are required as inputs, such as capacity for speed delay, travel time estimation method, diverted cars (\%), etc. Quick Zone (Mitretek Systems, 2004; Curtis, 2001) and QUEWZs (queue and user cost evaluation of work zones) (Copeland, 1998) are two similar, well-known deterministic simulation and analytic software tools. The closure number and duration of construction schedules of different highway work scenarios must be entered by users and are normally based on users' assumptions and experience (Lee et al., 2005). A similar effort called FLH-QuickZone, which was developed by Hardy et al. (2007), focused on accurately predicting queue lengths and delays for two-way, one-lane operations. Due to the simple data input, this kind of software has a limited capability to analyze complicated delay situations (Chen et al., 2010). All of these loss calculation methods can fall into the first category, which is characterized by mathematical calculations and expert experience in the determination of traffic flows.

Another way to determine transport costs and congestion is by using microscopic simulation tools. Unlike all the macroscopic and analytical tools which use a deterministic queuing model to compute the queue lengths microscopic simulation models such as VISSIM derive queue lengths based on car-following and lane changing models which is a more accurate representation of reality (Chatterjee, 2008). In this way, a complex problem is obtained which evaluates many criteria and gives more realistic results. In order to accurately use the simulation models for traffic analysis of work zones, it is necessary to calibrate the models to match the field conditions (such as lane capacity, queue lengths and lane utilization) by adjusting the driver behavior parameters. The default parameters in a simulation model including driving behavior parameters, truck characteristics and performance, are usually suggested for use while modeling normal traffic conditions (Chatterjee, 2008). The most widely used applications in the world for microscopic modeling of traffic flows are CORSIM and VISSIM. These programs do not exclude the model of work zones, so it is important re-create the traffic conditions in work zone and to set appropriate restrictions. However, default simulation tool calculations do not ensure the complete restoration of roadwork traffic activity. There are many undefined situations which are hardy can be described with formula.

\section{Research background}

The objective of current research is to investigate traffic performance of one traffic control strategies at single lane closures on two lane roads. This scenario is the most common situation in roadwork zones in Lithuania. Pre-timed signals are used but no deep investigation of traffic composition and density is done. This leads to huge traffic jams, time waste and increased emissions.

Travel time total is used as a performance measure. In order to evaluate the current situation in these sections, field studies were carried out to collect essential criteria which is needed to reconstruct the situation in a computer model. PTV Vissim software is selected for traffic representation and simulation. Since there is no specially designed roadworks model, default VISSIM calculations will be used. VISSIM has many models integrated which are related by each other and varies from user input data. Weidermann99 car following models was used in calculations, however driving conditions and culture deviates from standard situations.

The following data was collected: traffic flow (both directions), composition of heavy vehicles, length of section which is controlled by traffic lights, average speed, traffic lights green and red cycles. All collected data is represented in Table 1. View of work zone surroundings and driving conditions shown in Figure 1. Road 165 was selected due to high traffic management complexity. Roadwork zone divided into 4 different length stretches and managed by fixed temporary traffic light cycles. Traffic model was created for 1 roadwork zone section to evaluate simulation efficiency for current traffic situation and compare to other possible situations.

Table 1. Collected data of current situation

\begin{tabular}{|c|c|c|c|c|c|c|c|c|}
\hline \multirow{3}{*}{ Direction 1} & \multirow{3}{*}{$\begin{array}{c}\begin{array}{c}\text { Road } \\
\text { No }\end{array} \\
165\end{array}$} & \multirow{3}{*}{$\begin{array}{c}\text { WZ length } \\
1500 \mathrm{~m}\end{array}$} & \multicolumn{3}{|c|}{ Traffic } & \multirow{3}{*}{$\begin{array}{c}\text { Speed } \\
50 \mathrm{~km} / \mathrm{h}\end{array}$} & \multicolumn{2}{|c|}{ Traffic light span } \\
\hline & & & \multicolumn{2}{|c|}{ Total } & HGV & & Green & Red \\
\hline & & & $135 \mathrm{veh} / \mathrm{hour}$ & \multirow{2}{*}{$\begin{array}{c}3984 \\
\text { (AADT) }\end{array}$} & $12 \%$ & & $120 \mathrm{~s}$ & $560 \mathrm{~s}$ \\
\hline Direction 2 & 165 & $1500 \mathrm{~m}$ & $100 \mathrm{veh} / \mathrm{hour}$ & & $20 \%$ & $50 \mathrm{~km} / \mathrm{h}$ & $120 \mathrm{~s}$ & $560 \mathrm{~s}$ \\
\hline
\end{tabular}



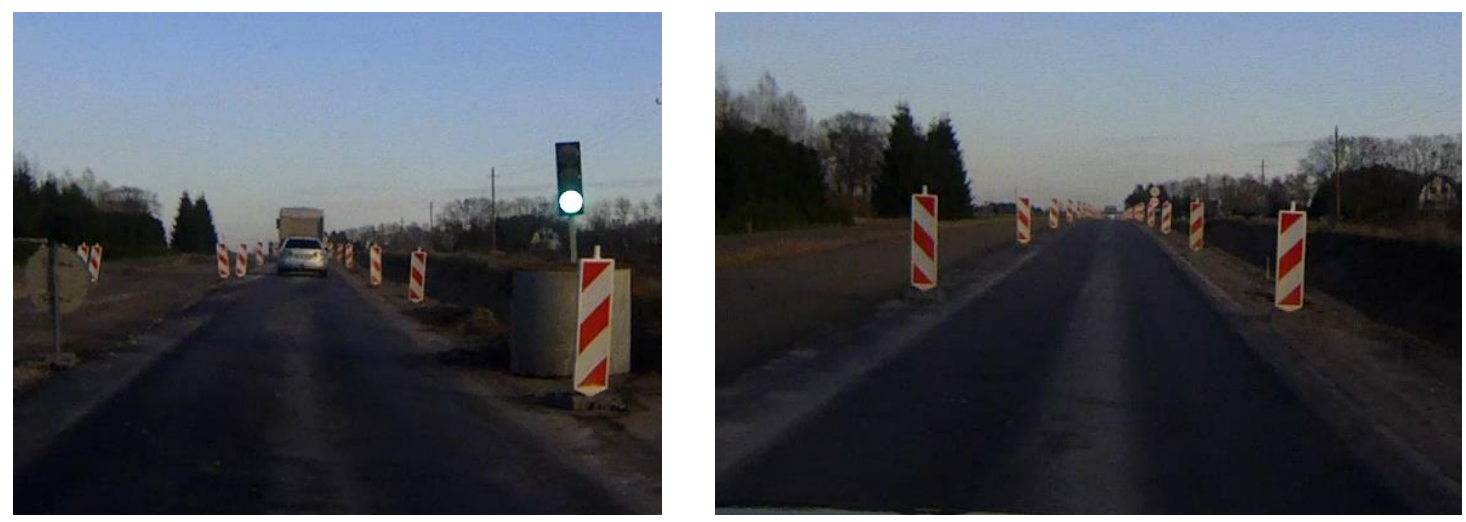

Figure 1. Work zone traffic management and driving conditions

Stochastic analytic approaches were utilized in this investigation since the use of microscopic traffic simulation method is involved in calculations. Vehicle input also used as stochastic approach but axial number was entered in the model.

\section{Results}

3 different models were created to evaluate different traffic control situations at single-lane roadwork zone. First model represents casual driving situation with no roadwork activity. Second model represents the current situation with gathered in-situ data. Third model created to determine the possible network performance benefits if simulation is used. Model shown in Figure 2 and results represented in Table 2.

Table 2. Results of different simulation scenarios

\begin{tabular}{|l|c|c|c|c|c|c|c|c|}
\hline & $\begin{array}{c}\text { Vehicles } \\
\text { arrived } \\
\text { (total) }\end{array}$ & $\begin{array}{c}\text { Speed } \\
\text { average, } \\
\mathrm{km} / \mathrm{h}\end{array}$ & $\begin{array}{c}\text { Total travel } \\
\text { time, } \\
\text { seconds }\end{array}$ & $\begin{array}{c}\text { Delay stop } \\
\text { (total), } \\
\text { seconds }\end{array}$ & $\begin{array}{c}\text { Total travel } \\
\text { time (cars), } \\
\text { seconds }\end{array}$ & $\begin{array}{c}\text { Total travel } \\
\text { time (HGV), } \\
\text { seconds }\end{array}$ & $\begin{array}{c}\text { CO } \\
\text { total, } \\
\text { grams }\end{array}$ & $\begin{array}{c}\text { NOx } \\
\text { total, } \\
\text { grams }\end{array}$ \\
\hline No roadworks & 241 & 92 & 23936 & 0 & 20440 & 3495 & 409 & 80 \\
\hline Current situation & 204 & 12 & 168560 & 127750 & 145964 & 22596 & 2248 & 437 \\
\hline Proposed model & 224 & 25 & 84905 & 42732 & 73099 & 11806 & 1187 & 231 \\
\hline
\end{tabular}

No roadworks situation represents casual driving conditions in the road sketch of $2500 \mathrm{~m}$ length. Speed limit before roadworks was $90 \mathrm{~km} / \mathrm{h}$, for this reason the same speed limit was selected as limiter in the VISSIM simulation model. Current situation results represents the in-situ collected data used in the simulation model. Proposed model is created by author to find the best pre-timed signals cycle scenario when total travel time is used as performance indicator.

Naturally, no roadworks scenario is the best option with the best performance results however road maintenance or rehabilitation is needed from time to time. It is crucial to ensure the best network performance and validated model can help to sneak peek the future.

Analysis shown that it takes $\sim 97$ seconds for light vehicles and $\sim 112$ seconds for HGV to pass $2500 \mathrm{~m}(1500 \mathrm{~m}$ actual road work zone and $500 \mathrm{~m}$ length to reach work zone on both directions) length road sketch in no roadworks scenario. Speed limit was selected as $90 \mathrm{~km} / \mathrm{h}$ however stockhastic method was selected which means every road user has some freedom to deviate from input data. Considering that there is no penalty in Lithuania when speed limit is exceeded up to $10 \mathrm{~km} / \mathrm{h}$, average speed of $92 \mathrm{~km} / \mathrm{h}$ in model seems to be reasonable. Current situation has worst network performance results. This is caused because of lack investigation of real traffic conditions as mentioned before. Less vehicles arrived to final destination during the same simulation time (3600 seconds). Light vehicles took $~ 830$ seconds long journey to cross the same $2500 \mathrm{~m}$ lenght road stretch. "Proposed model" differs from "current situation" model only by changed pre-timed signals cycle duration. Deep investigation of traffic flow was done to ensure, that proposed traffic light cycles reduce time costs for road users and safe traffic conditions. In-situ collected average driving speed data was used to calculate time gap to cross the roadworks, taking into account clearance time and HGV speed differences. "Proposed model" decreases total travel time by 83655 seconds (more than 23 hours). It is far away from "no roadworks" situation, however these two different situations cannot be compared directly. $\sim 375$ seconds are needed for cars to cross the roadworks in "proposed model" scenario, which is $\sim 455$ seconds less than current situation. 
$\mathrm{CO}$ and NOx emissions also taken into account but not in all $2500 \mathrm{~m}$ long stretch. Emission calculations zones selected by experience. The highest concentrations of particulate matter occur where vehicles are standing with running engines or starting to accelerate. Therefore, it was decided to monitor emissions only at places where pre-timed traffic signals are located. These zones highlighted in Figure 2. Traffic produces $47 \%$ less CO and NOx emissions in "proposed model" comparing to "current situation" scenario.

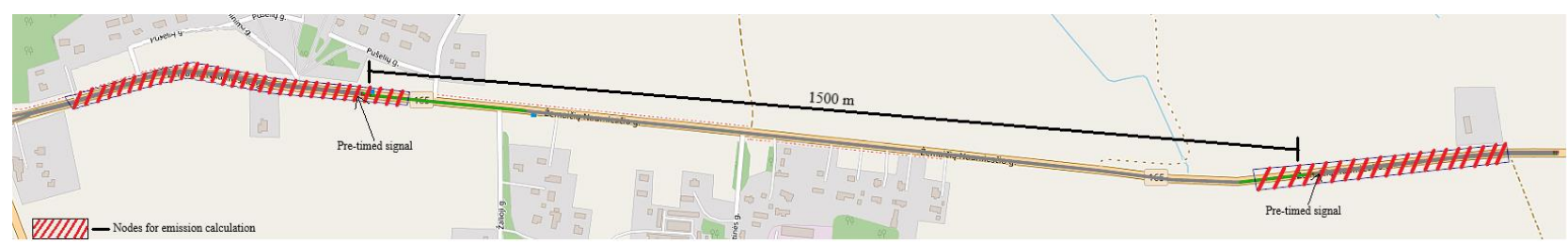

Figure 2. Created pre-timed signalled roadwork zone model

Since the travel time was is used as network performance indicator, it could be expressed through the user costs. All calculations were made regarding to "Methodology for calculating conversion factors and assessing socioeconomic impacts (benefits/damages)" which was released in 2019 and adapted for Lithuania. User travel costs calculated with given cost values and represented in Table 3. Calculations made taking into account that 50/50 share of users are going to work/leisure. The purpose of driving treated with different amount of money. HGV costs calculated taking into account that each HGV load is approximately 12 tones. This is recommended load value in Lithuania to use in cost-benefit analysis calculations.

Costs-benefit analysis clearly shows, that "proposed model" could save $\sim 55 \%$ more money for traffic users by estimating their time cost.

Table 3. User cost analysis for different traffic management scenarios

\begin{tabular}{|l|c|c|c|c|}
\hline & Cost for cars & Cost for HGV & Total cost for all vehicles & Cost NO \\
\hline No roadworks & $9794,02 €$ & $20674,00 €$ & $30468,02 €$ & $0,51 €$ \\
\hline Current situation & $50406,85 €$ & $102044,11 €$ & $152450,96 €$ & $2,82 €$ \\
\hline Proposed model & $23429,26 €$ & $45982,00 €$ & $69411,26 €$ & $1,49 €$ \\
\hline
\end{tabular}

\section{Conclusions}

This paper presents a study on traffic control at single lane closures on two-lane roads. Three different traffic management scenarios were investigated by this study for their performance under different conditions. Pre-timed signal cycles and traffic management schemes were investigates as variables. The most important findings of this study are:

1. Delay at roadwork zones can be reduced significantly by using simulation models with investigated traffic flows and composition before actual work started.

2. Proposed traffic model can reduce total travel time for road users by $49.63 \%$ and user costs by $\sim 55 \%$.

3. Appropriate traffic control measures or variable message signs with remaining prie-timed signal downtime could possibly reduce inadequate behaviour in roadwork zones.

4. Proposed model is only effective when roadwork machinery does not interfere with regular traffic and does not distort driving conditions.

5. Author recommend further research on the interaction between construction operations and traffic operations at this type of roadworks. More variables could be taken into calculations such as work zone lenght, average speed, traffic flow and composition or traffic directional split. Research is also recommended on the use of new technologies in developing more advanced portable traffic control systems for roadwork zones with single lane and two way traffic control.

\section{Author contributions}

DS and IJ conceived the study about traffic modelling within roadwork zones. DS was responsible for model creation, modelling process, data collection and analysis, economical calculations and result data interpretation. IJ was responsible for literature collection and analysis and traffic count calculations. DC responsible for corrections, conclusions, ideas distribution. 


\section{References}

Birst, S., Baker, J., \& Khaled, S. (2007). Comparison of traffic simulation models with hom 2000 methodology using various traffic levels under pretimed signal control. Paper presented at the 86th Annual Meeting of the Transportation Research Board, Washington, D.C.

Base-lining Road Works Safety on European Roads. (2014). CEDR Call 2012: safety input data definition document for EuRoWCas. http://browser.zag.si/en/index.php

Carr, I. R. (2000). Arctm. Journal of Construction Engineering and Management, 9364, 52-60.

Chatterjee, I. (2008, December). Replication of freeway work zone capacity values in a microscopic simulation model (ProQuest Dissertations and Theses). https://search.proquest.com/docview/905174529? accountid=188395

Chen, E., \& Tarko, A. P. (2014). Modeling safety of highway work zones with random parameters and random effects models. Analytic Methods Accident Research, 1, 86-95. https://doi.org/10.1016/j.amar.2013.10.003

Chen, Y., Qin, X., Noyce, D. A., \& Lee, C. (2010). Interactive process ofmicrosimu- lation and logistic regression for short-term work-zone traffic diversion. Transportation Engineering, 136(3), 243-254. https://doi.org/10.1061/(ASCE)TE.1943-5436.0000087

Copeland, L. (1998). User's manual for QUEQZ-98 (Rep. No. 1745-2). Texas Transportation Institute, Texas A\&M University.

Curtis, D. (2001). QuickZone. Public Roads, 65(1).

Debnath, A. K., \& Blackman, R. A. (2014, February 5). Effectiveness of pilot car operations in reducing speeds in a long-term rural highway work zone. Paper presented at the Proceedings of the Transportation Research Board 93 ${ }^{\text {rd }}$ Annual Meeting, Washington, DC, USA.

Hardy, M. H., Larkin, J. J., Wunderlich, K. E., \& Nedzesky, A. J. (2007). Estimating user costs and economic impacts of roadway construction in six federal lands projects. Transportation Research Record, 1997(1), 48-55. https://doi.org/10.3141/1997-07

Hadiuzzaman, M., Lu, M., \& Abourizk, S. M. (2014). Modelling the impact of work-zone traffic flows upon concrete construction: a high level architecture based simulation framework. Canadian Journal of Civil Engineering, 41(2), 144-153. https://doi.org/10.1139/cjce-2013-0103

La Torre, F., Domenichini, L., \& Nocentini, A. (2017). Effects of stationary work zones on motorway crashes. Safety Science, 92, 148-159. https://doi.org/10.1016/j.ssci.2016.10.008

Lee, E. B., Harvey, J. T., \& Samadian, M. M. (2005). Knowledge-based scheduling analysis software for highway rehabilitation and reconstruction projects. Transportation Research Record, 1907(1), 15-24. https://doi.org/10.1177/0361198105190700103

Mitretek Systems. (2004). QuickZone case studies: The application of QuickZone in eight common construction projects. https://ops.fhwa.dot.gov/wz/traffic_analysis/quickzone/casestudies/qz_case_studies/qz_case_study.pdf

$\mathrm{Ng}, \mathrm{M} .$, \& Waller, S. T. (2010). A computationally efficient methodology to characterize travel time reliability using the fast Fourier transform. Transportation Research Part B: Methodologic, 44(10), 1202-1219. https://doi.org/10.1016/j.trb.2010.02.008

Schnell, T., Mohror, J. S., \& Aktan, F. (2002). Evaluation of traffic flow analysis tools applied to work zones based on flow data collected in the field. Transportation Research Record: Journal of the Transportation Research Board, 1811(1), 57-66. https://doi.org/10.3141/1811-07

Wu, Z., Sharma, A., Mannering, F. L., \& Wang, S. (2013). Safety impacts of signal-warning flashers and speed control at highspeed signalized intersections. Accident Analysis \& Prevention, 54, 90-98. https://doi.org/10.1016/j.aap.2013.01.016 